\title{
The Increase in a Brittle-to-ductile Transition Temperature in Fe-Al Single Crystals
}

\author{
Masaki TANAKA, ${ }^{1)}$ Keiki MAENO, ${ }^{1)}$ Kenji HIGASHIDA, ${ }^{1)}$ Masahiro FUJIKURA ${ }^{2)}$ and Kohsaku USHIODA ${ }^{3)}$ \\ 1) Department of Materials Science and Engineering, Kyushu University, 744 Motooka, Fukuoka, 819-0395 Japan. \\ 2) Yawata R\&D Lab., Technical Development Bureau, Nippon Steel Corporation, 1-1 Tobihata, Tobata, Kitakyushu, $804-8501$ \\ Japan. $\quad 3$ 3) Technical Development Bureau, Nippon Steel Corporation, 20-1 Shintomi, Futtsu, Chiba, $293-8511$ Japan.
}

(Received on February 9, 2011; accepted on March 22, 2011)

\begin{abstract}
The effect of aluminium concentration on a brittle-to-ductile transition (BDT) has been investigated in Fe-Al single crystals. The BDT temperatures in Fe-4mass\%Al and Fe-8mass\%Al crystals with $<100>$ specimen axis were measured by an instrumental falling weight impact tester, indicating that the BDT temperature in $\mathrm{Fe}-8 \% \mathrm{Al}$ is higher than that in $\mathrm{Fe}-4 \% \mathrm{Al}$. Twin-twin intersections were seen on fracture surfaces in Fe-8\%Al tested at low temperatures, which shows that the intersection was the origin of a brittle fracture. In order to highlight the effect of deformation twinning on the BDT behaviour, specimens with the $\langle 110\rangle$ axis were also employed to suppress the onset of deformation twinning during the impact tests. The BDT temperature in Fe-8\%Al was found to be decreased by suppressing deformation twinning, which indicates that deformation twinning is a key mechanism behind increasing the BDT temperature in $\mathrm{Fe}-\mathrm{Al}$ single crystals. A model to explain the increase in the BDT temperature with aluminium content is also presented.
\end{abstract}

KEY WORDS: ferrite; brittle fracture; steel; deformation twinning; dislocations; aluminium.

\section{Introduction}

Controlling the mechanical properties of steels is one of the most important issues to enhance their reliability in the usage as structural materials. It is necessary to add proper elements in steels to obtain the mechanical properties demanded. Increasing in the amount of elements in ferritic steels generally increases the yield stress at room temperature, which is well known as solid solution hardening. It is induced by the interaction between dislocations and solute atoms added. It is also well-known that yield stress in ferritic steels is markedly increased by lowering deformation temperature. Such strong dependence of temperature on yield stress is not observed in austenitic steels. It is due to the thermally activated process of dislocation glide, overcoming a relatively higher Peierls potential in ferritic steels with bcc structures than that in austenitic steels with fcc structures in which the Peierls potential is inevitably low. The increase in the yield stress with decreasing temperature is suppressed by adding particular solid solution elements such as silicon, ${ }^{1,2)}$ nickel $^{2)}$ and copper, ${ }^{3)}$ and then the yield stress becomes lower than that of pure iron at low temperatures. The effect is known as solid solution softening. Figure 1(a) shows temperature dependence of yield stress from $\mathrm{Fe}, \mathrm{Fe}-4 \mathrm{at} . \% \mathrm{Ni}$ and $\mathrm{Fe}-4 \mathrm{at} . \% \mathrm{Si}$, which is reconstructed from Table 2 in Ref. (2). It indicates that the value of yield stress of $\mathrm{Fe}-4 \mathrm{at} . \% \mathrm{Ni}$ and $\mathrm{Fe}-4 \mathrm{at} . \% \mathrm{Si}$ were lowered by up to $84 \%$ and $77 \%$ of that in pure iron at $77 \mathrm{~K}$, respectively. Since the yield stress has a strong relation to dislocation mobility, the decrease in the yield stress at lower tempera-
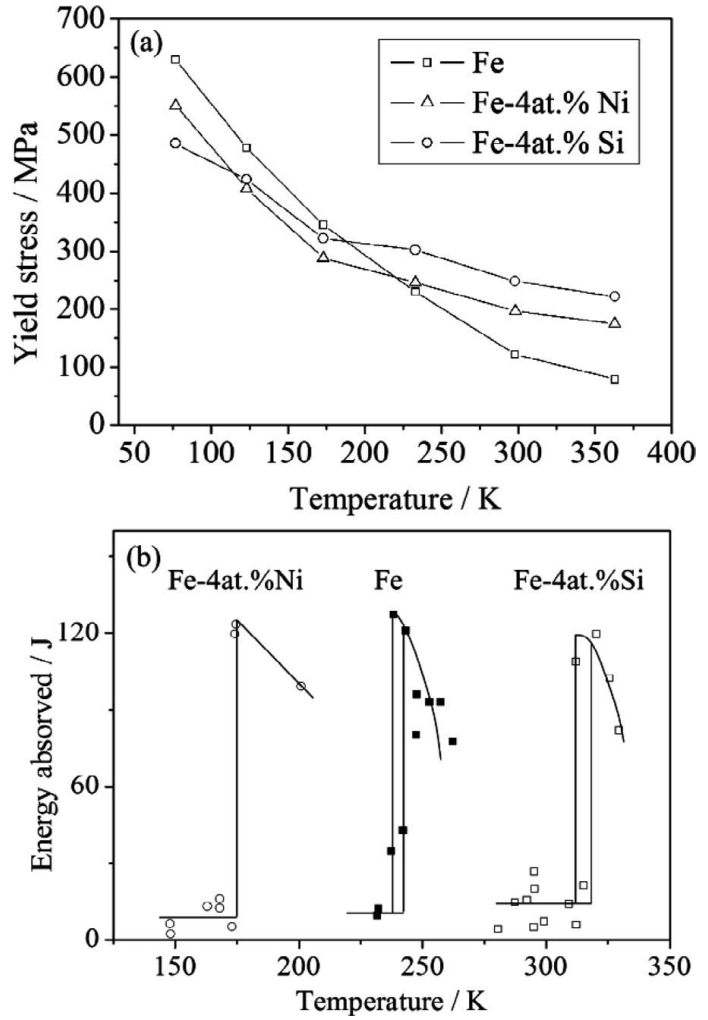

Fig. 1. (a) Yield stress from $\mathrm{Fe}, \mathrm{Fe}-4 \mathrm{at} . \% \mathrm{Si}$ and $\mathrm{Fe}-4 \mathrm{at} . \% \mathrm{Ni}$ obtained by Chen and Gerberich. This figure was reconstructed from Table 2 in Ref. (2). (b) Charpy V-notch impact energy as a function of test temperature for $\mathrm{Fe}, \mathrm{Fe}-$ $\mathrm{Ni}$ and $\mathrm{Fe}-\mathrm{Si}$ alloys. The data in this figure are referred from Figs. 1 and 2 in Ref. (8). 
tures suggests that the dislocation mobility in Fe-4at.\%Ni and $\mathrm{Fe}-4$ at.\%Si should be higher than that in pure iron at low temperatures. The increase in the dislocation mobility by adding those solute atoms suggests that the brittle-toductile transition (BDT) temperatures of $\mathrm{Fe}-4 \mathrm{at} . \% \mathrm{Ni}$ and $\mathrm{Fe}-4 \mathrm{at} . \% \mathrm{Si}$ should be lower than that of pure iron since the BDT behaviour is controlled by dislocation glides. ${ }^{4-7)}$ Figure 1(b) shows the temperature dependence of V-notched impact energy from $\mathrm{Fe}, \mathrm{Fe}-4 \mathrm{at} . \% \mathrm{Ni}$ and $\mathrm{Fe}-4$ at.\%Si alloys summarised from Figs. 1 and 2 in Ref. (8). The absorbed energy in each alloy exhibits abrupt increase at a certain temperature, indicating the sharp transitions of fracture modes from a brittle manner to a ductile one, which is commonly seen in ferritic steels. It is to be noted here that the BDT temperatures in $\mathrm{Fe}-4 \mathrm{at} . \% \mathrm{Ni}$ and $\mathrm{Fe}-4$ at.\% $\mathrm{Si}$ are approximately $70 \mathrm{~K}$ lower and higher than that in $\mathrm{Fe}$, respectively. The effect of $\mathrm{Si}$ on the BDT is contrary to that of $\mathrm{Ni}$ whereas both of them induce solid solution softening at low temperatures. It suggests that there should be other controlling factors, besides the slip dislocation glide, which should be considered to understand the BDT behaviour in ferritic steels.

Honda $^{9)}$ and Narita et al. ${ }^{10)}$ pointed that deformation twinning plays an important role on brittle fracture in $\mathrm{Fe}-\mathrm{Si}$ single crystals. Their works suggest that it is also necessary to take into account the role of deformation twinning for understanding the mechanism behind the inverse effects of $\mathrm{Ni}$ and $\mathrm{Si}$ on the BDT behaviour shown in Fig. 1. It was reported that addition of aluminium in ferritic steels also leads to solid solution softening at low temperatures. ${ }^{11)}$ The effects of aluminium on mechanical property are very similar to those of silicon although the amount of the effects is weaker than those of silicon. For example, the increase in the yield stress per at. $\%$ aluminium is around the half of that per at.\% silicon at room temperature. ${ }^{12)}$ Slip bands in $\mathrm{Fe}-\mathrm{Al}$ show very straight as well as slip bands seen in Fe-Si while those in ferrites are generally wavy due to the frequent cross-slipping, which indicates that the cross-slipping is prohibited by the addition of aluminium or silicon. Such common effects of aluminium and silicon on the mechanical behaviours of the ferritic alloys suggest that the BDT temperature in $\mathrm{Fe}-\mathrm{Al}$ should be higher than that in pure iron as well as Fe-Si seen in Fig. 1.

The first purpose in this paper is, therefore, to investigate the change in the BDT temperature with increasing aluminium content, by measuring the temperature dependence of absorbed energies during three point bending impact tests. Secondly, in order to highlight the effect of deformation twinning on the BDT behaviour with increasing aluminium content, the shift of the BDT temperature was investigated by employing specimens with the crystal orientation in which deformation twinning is suppressed. In the present paper, it will be discussed why the BDT temperature increases with increasing in aluminium content whereas solid solution softening is induced by the addition of aluminium, where the competitive operations of deformation twinning and slip deformation are taken into account.

\section{Experimental}

Single crystalline Fe-mass $4 \% \mathrm{Al}$ and $\mathrm{Fe}-$ mass $8 \% \mathrm{Al}$ were employed, the chemical compositions of which are shown in Table 1, respectively. Miniature size specimens of $1 \times 1 \times$ $24 \mathrm{~mm}^{3}$ were cut out for subsequent impact tests. The beam distance was set to be $20 \mathrm{~mm}$. Two different specimen orientations were employed as shown in Fig. 2. One type was that cubic orientations were facing to the specimen surfaces as shown in the coordinates of Fig. 2(a). The applied tensile direction in bending was along [100] around the notch. The other type was that the specimen axis was $45^{\circ}$ rotated with respect to [001] and then the surface orientation was as indicated in Fig. 2(b), in which deformation twinning can be prohibited $^{9)}$ with the applied tensile direction of [110] in bending. A V-shaped notch was introduced at the tensile side in the specimen surface by using an abrasive blade. The three-point-bending impact tests were carried out by using an instrumental falling weight tester (TANAKA: TM-H$150)$ at various temperatures. The absorbed energy at fracture was measured from a load-displacement curve obtained during the impact tests.

\section{Results}

Figure 3 shows temperature dependences of the energy absorbed at fracture in $\mathrm{Fe}-4 \% \mathrm{Al}$ and $\mathrm{Fe}-8 \% \mathrm{Al}$ specimens. The average absorbed energy at a lower-shelf is $6.6 \mathrm{~kJ} / \mathrm{m}^{2}$ in both $\mathrm{Fe}-4 \% \mathrm{Al}$ and $\mathrm{Fe}-8 \% \mathrm{Al}$. The BDT temperature was determined as the one at which the absorbed energy shows the middle value between those of the lower-shelf and the upper-shelf. The BDT temperature in $\mathrm{Fe}-4 \% \mathrm{Al}$ was determined to be approximately $180 \mathrm{~K}$ while that in $\mathrm{Fe}-8 \% \mathrm{Al}$ was approximately $320 \mathrm{~K}$. The increase in aluminium content increases the BDT temperature as well as that in silicon, which is contrary to the effect of nickel on the BDT temperature. In silicon added ferritic steels, the onset of deformation twinning brings cleavage, ${ }^{2)}$ which suggests the increase in the BDT temprature is induced by deformation twinning in $\mathrm{Fe}-\mathrm{Si}$ alloys. It also suggests that the change in the BDT temprature in $\mathrm{Fe}-\mathrm{Al}$ is due to the change in twinning behaviour with incraseing aluminum content. In order to analyse the twinning bahivour in aluminium added ferritc steels,

Table 1. Chemical composition of the specimens employed.

\begin{tabular}{cccccccc}
\hline & C & Si & Mn & P & S & Al & Fe \\
\hline Fe-4\%Al & 0.0004 & 0.005 & $<0.002$ & $<0.002$ & 0.0013 & 4.22 & bal. \\
Fe-8\%Al & 0.0012 & 0.007 & $<0.002$ & $<0.002$ & 0.0012 & 8.14 & bal.
\end{tabular}

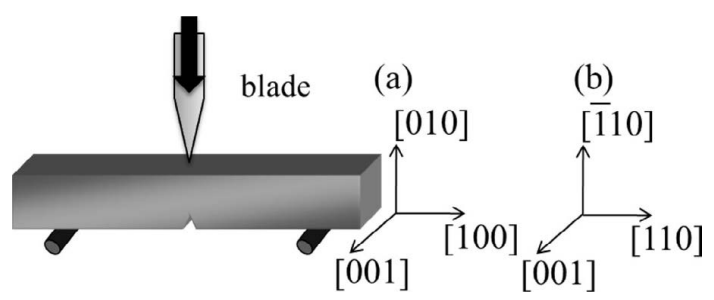

Fig. 2. Schematic drawing of the impact test specimen. Two different geometries were chosen as indicated in (a) and (b) to highlight the effect of twinning on the brittle-to-ductile transition behaviour. 


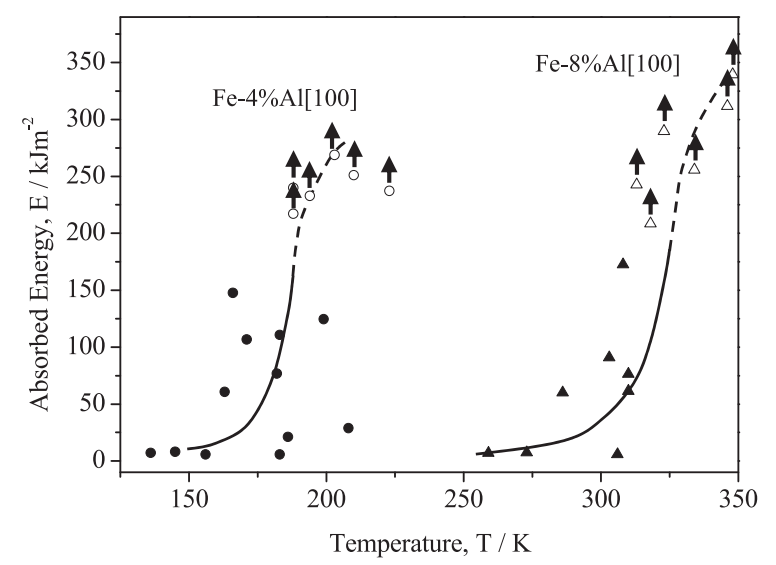

Fig. 3. Temperature dependence of absorbed energy obtained by falling weight impact tests. The specimen geometry is one indicated by (a) in Fig. 2. Open symbols indicate that the specimens were not separated into two pieces, which means the actual absorbed energy is higher than the values. The BDT temperature in $\mathrm{Fe}-8 \% \mathrm{Al}$ is higher than that in $\mathrm{Fe}$ $4 \% \mathrm{~A} 1$.

fracture surfaces and specimen side surfaces were observed by using scanning electron micrsocopy (SEM).

Figure 4 shows SEM images of fracture surfaces and side surfaces tested at $145 \mathrm{~K}(\mathrm{Fe}-4 \% \mathrm{Al})$ and $259 \mathrm{~K}(\mathrm{Fe}-8 \% \mathrm{Al})$. The specimens observed were tested and fractured in a brittle manner at the temperatures in the lower-shelf in Fig. 3. The notch roots locate in the bottom of the figures. The crack extended along the [010] direction as seen in Figs. 4(e) and 4(f). The both fracture surfaces are the (100) cleavage planes of bcc metals. Enlarged images of the areas pointed by dashed rectangles in Figs. 4(a) and 4(b) are shown in Figs. 4(c) and 4(d), respectively. The fracture surface of $\mathrm{Fe}-4 \% \mathrm{Al}$ demonstrates typical river patterns as seen in Fig. 4(c) where the crack initiation site is indicated by an arrow near bottom of the figure. The crack initiation site in $\mathrm{Fe}-8 \% \mathrm{Al}$ is located on a twin-twin intersection, which lies along [011] directions. In this type of intersection, dislocations of the (211) twin collide with a $(2 \overline{1} \overline{1})$ twin. Line contrasts observed along [120] and [120] directions in Fig. 4(f) elucidate the activated twin system around the notch. The traces of twinning systems observed in Figs. 4(b), 4(d) and 4(f) are schematically shown in Fig. 4(g); the lines observed along [120] in Fig. 4(f) are traces of (211) twinning planes; those along [120] are the traces of $(2 \overline{1} \overline{1})$ twinning planes. The more number of twinning and the twin-twin intersections are observed in $\mathrm{Fe}-8 \% \mathrm{Al}$ as shown in Fig. 4(f). It was pointed out that specific types of twin-twin intersections can be a crack initiation site in Fe-Si single crystals. ${ }^{9,10,13)}$ There are four equivalent twinning systems with the same Schmid factor of 0.472 under the tensile direction of [100] in a bcc structure, i.e., (2 $\overline{1} 1)[11 \overline{1}],(2 \overline{1} \overline{1})[111],(21 \overline{1})[1 \overline{1} 1]$ and (211)

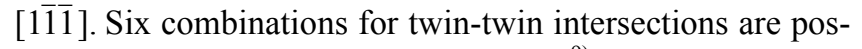
sible as summarised in Table 2. Honda ${ }^{9)}$ demonstrated that when the direction of intersection of two twinning planes is parallel to $<011>$, termed as $<011>$ type in Table 2 , the intersection can become the initiation site of cleavage fracture. Figure 5 illustrates a schematic drawing of atomic configurations of matrix and twinned area seen from the

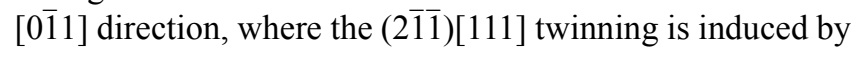

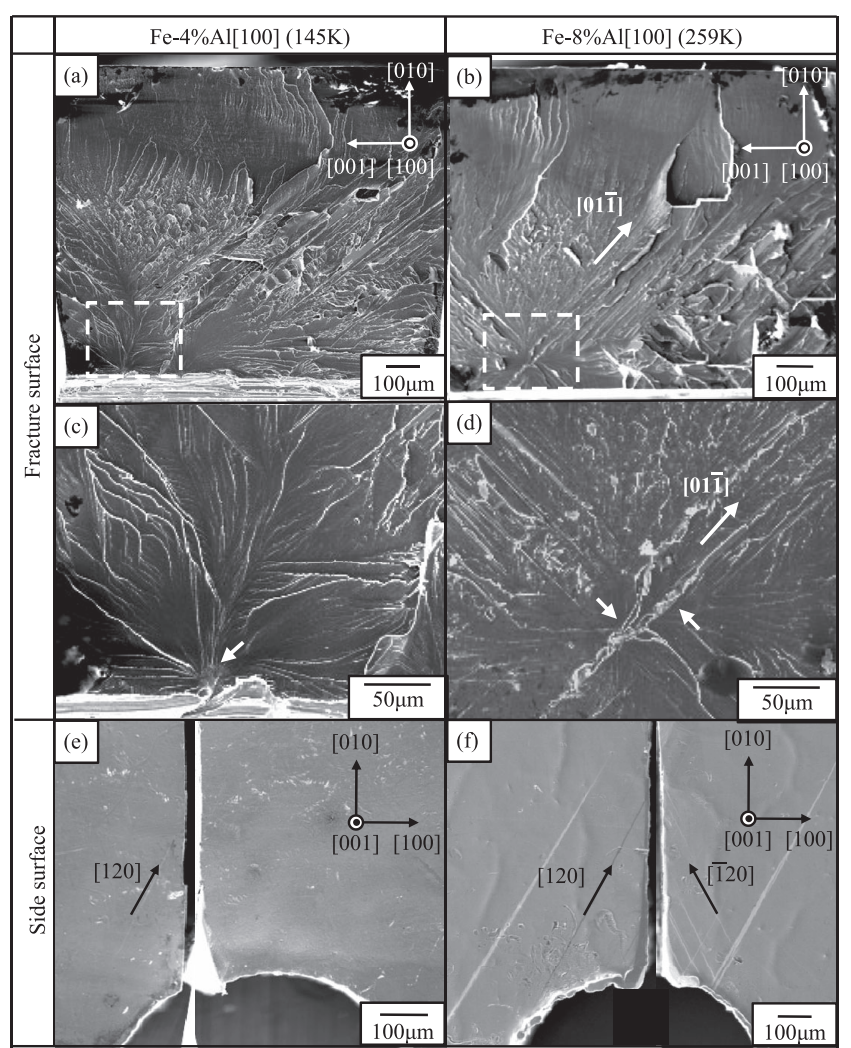

(g)

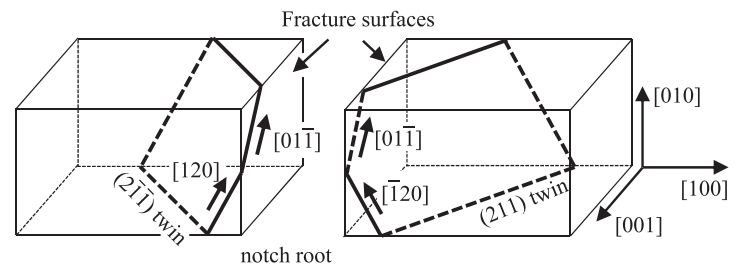

Fig. 4. SEM images observed after the impact tests in Fig. 3 from $\mathrm{Fe}-4 \% \mathrm{Al}$ and $\mathrm{Fe}-8 \% \mathrm{Al}$, respectively. (c) and (d) are enlarged images of the dashed rectangles in (a) and (b), respectively. Crack initiation sites are indicated by arrows in (c) and (d). The more number of twins are seen in Fe$8 \% \mathrm{Al}$. A twin-twin intersection is seen in Fig. 4(d). A schematic drawing of the geometry of twins and their traces on the specimen surface for $\mathrm{Fe}-8 \% \mathrm{Al}$ are shown in Fig. 4(g).

Table 2. Types of twin intersections for bcc crystals.

\begin{tabular}{cccc}
\hline Type & \multicolumn{2}{c}{ Twining plane } & Direction of intersection \\
\hline \multirow{2}{*}{$<011>$ type } & $(2 \overline{1} \overline{1})$ & $(211)$ & {$[01 \overline{1}]$} \\
& $(2 \overline{1} 1)$ & $(21 \overline{1})$ & {$[011]$} \\
\hline \multirow{2}{*}{$<120>$ type } & $(2 \overline{1} 1)$ & $(2 \overline{1} \overline{1})$ & {$[120]$} \\
& $(2 \overline{1} 1)$ & $(211)$ & {$[\overline{1} 02]$} \\
& $(21 \overline{1})$ & $(2 \overline{1} \overline{1})$ & {$[102]$} \\
& $(21 \overline{1})$ & $(211)$ & {$[\overline{1} 02]$} \\
\hline
\end{tabular}

the resolved shear stress on the $(2 \overline{1} \overline{1})$ twinning plane indicated by arrows "A". When a (211)[1시] twinning in the matrix collides with the interface of the (21) 1 [111] twinning which has been formed, the direction of shear stress induced by the applied stress and (211)[1 $\overline{1} \overline{1}]$ twinning is one indicated by " $\mathrm{B}^{\mathrm{P}}$ ". However, the twinning direction in $(2 \overline{1} \overline{1})[111]$ twinning layers is one indicated by " $\mathrm{B}$ " which is anti-twinning direction so that the (211)[1 $\overline{1} \overline{1}]$ twinning cannot pene- 


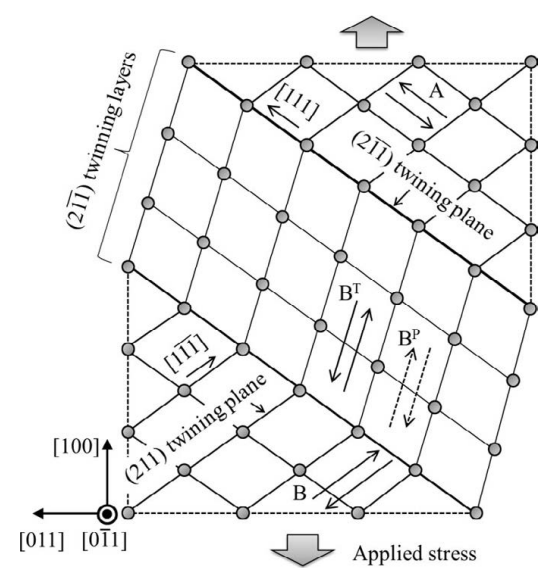

Fig. 5. Schematic drawing of an atomic configuration on an identical $(0 \overline{1} 1)$ plane, seen from [011], showing the change in

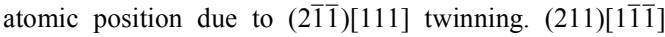
twins cannot penetrate $(2 \overline{1} \overline{1})$ twinning layers since the twin-

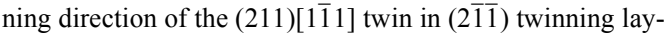
ers is an anti-twinning direction.

trate the $(2 \overline{1} \overline{1})[111]$ twinning layers. The collision of twinning induces large stress concentration, which will be

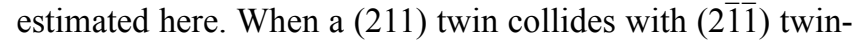
ning layers, the concentrated shear stress, $\tau_{c}$, is estimated by following equations; ${ }^{9}$ )

$$
\begin{gathered}
\tau_{c}=n \tau, \ldots \\
\tau=0.472 \sigma, \\
n=\frac{\sqrt{6} d}{a},
\end{gathered}
$$

Where $n$ is the number of twinning layers in the colliding twin, $\tau$ is the external shear stress, $\sigma$ is the external tenstion stress, $d$ is the thickness of the stopped twin and a is the lattice constant. The tensile stress on the (001) plane is derived from Eqs. (1), (2) and (3):

$$
\tau_{c, 001}=\frac{n \tau}{\sqrt{3}}
$$

Here, $\tau_{c, 001}$ was estimated to be around $600 \mathrm{GPa}$ with $d=0.5$ $\mu \mathrm{m}$ under the $\left.\sigma=490 \mathrm{MPa},{ }^{9}\right)$ which is large enough to induce a cleavage fracture. Figure 4(d) shows twin-twin intersections of (211) and (2 $\overline{1} \overline{1})$ twins on the (001) fracture surface, which is along [011] directions. This pair of deformation twinning is the $<011>$ type as shown in Fig. $4(\mathrm{~g})$ and Table 2 . The crack initiation sites are indicated by arrows in Fig. 4(d).

It is revealed in this study that the intersection of $<011>$ type deformation twins plays an important role on the increase in the BDT temperature in $\mathrm{Fe}-8 \% \mathrm{Al}$ alloys. It suggests that the BDT temperature should be decreased by suppressing the deformation twins. One of the methods to suppress deformation twinning in single crystalline alloys is to put the tensile direction along $<110>$. ${ }^{9)}$ In order to highlight the effect of deformation twinning on the BDT behaviour, another impact test was performed by changing the crystallographic orientations in the specimen; the longitudinal direction of the specimen was changed to be [110] as shown with the index axes Fig. 2(b) where the tensile stress perpendicular to the notch is along the [110] direction.

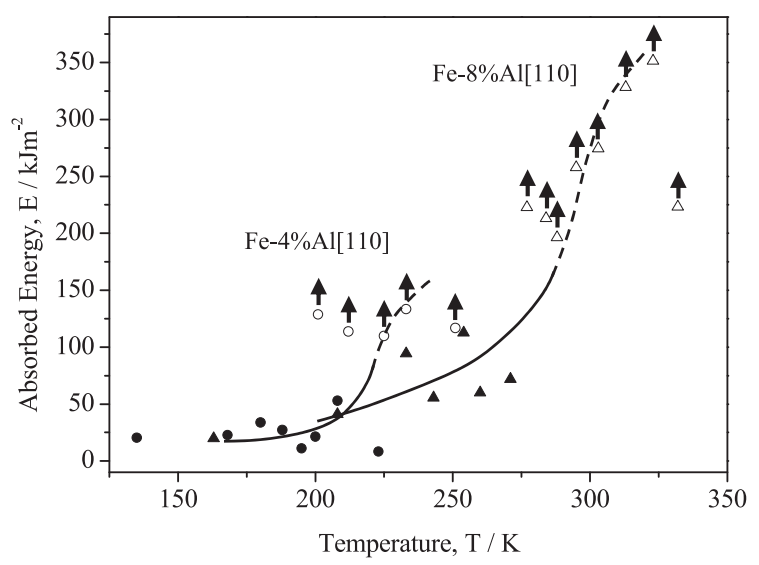

Fig. 6. The temperature dependence of absorbed energy in the specimen geometry of (b) in Fig. 2, where deformation twins are prohibited. The BDT temperature in $\mathrm{Fe}-8 \% \mathrm{Al}$ is decreased form that in Fig. 3. Open symbols indicate that the specimens were not separated into two pieces as seen in Fig. 3 .

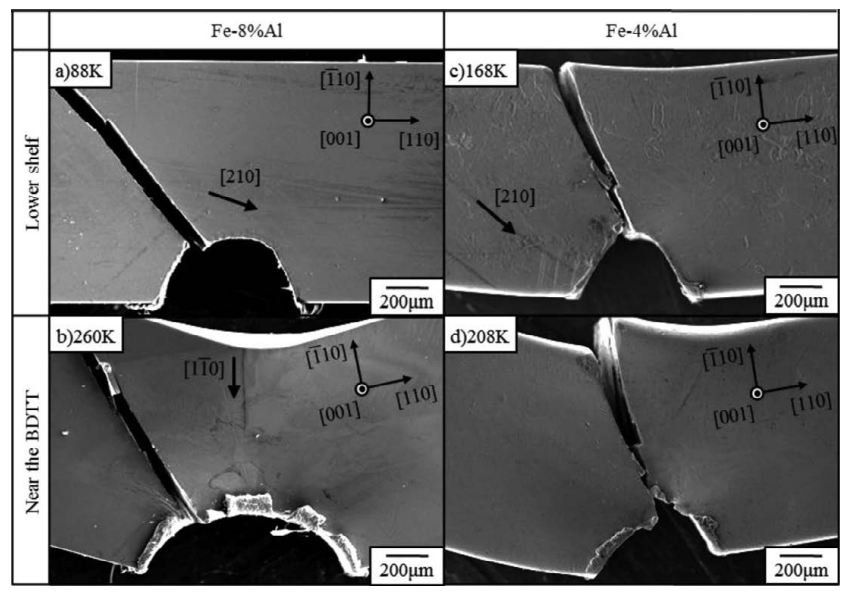

Fig. 7. SEM images observed after the impact tests in Fig. 6 from $\mathrm{Fe}-8 \% \mathrm{Al}$ and $\mathrm{Fe}-4 \% \mathrm{Al}$. Crack are extending along [ $\overline{1} 00]$, indicating the cleavage plane is (100) plane. There are no apparent signs of twin-twin intersections in these geometry. (a) $\mathrm{Fe}-8 \% \mathrm{Al}$ fractured at $88 \mathrm{~K}$, (b) $\mathrm{Fe}-8 \% \mathrm{Al}$ fractured at $260 \mathrm{~K}$, (c) $\mathrm{Fe}-4 \% \mathrm{Al}$ fractured at $168 \mathrm{~K}$, (d) Fe-4\%Al fractured at $208 \mathrm{~K}$.

Figure 6 shows the temperature dependence of absorbed energy at fracture obtained from $\mathrm{Fe}-4 \% \mathrm{Al}$ and $\mathrm{Fe}-8 \% \mathrm{Al}$. The longitudinal direction of the specimens are along [110]. The BDT temperature in $\mathrm{Fe}-8 \% \mathrm{Al}$ is decreased to be $289 \mathrm{~K}$ from $320 \mathrm{~K}$ of that in Fig. 3. Figures 7(a) and 7(b) show SEM images of the specimen surfaces of $\mathrm{Fe}-8 \% \mathrm{Al}$ fractured at $88 \mathrm{~K}$ and $260 \mathrm{~K}$. A crack propagated along the [100] direction from the notch root, indicating that the crack planes are cleavage plane of (010). The specimen hardly deformed plastically at $88 \mathrm{~K}$ as shown in Fig. 7(a) in lowershelf of the absorbed energy curve while the specimen was bent by slip deformation at $260 \mathrm{~K}$ as shown in Fig. 7(b), which is close to the BDT temperature. A marking along [1] 0$]$ is a trace of deformation twinning which was induced around the compressive side of the bending specimen. The notch was blunted due to the remarkable slip deformation, and no apparent marking of deformation twinning intersections was observed around the crack although a few twin- 
ning traces along [210] are seen near the notch. It suggests that BDT temperature is decreased by supressing the deformation twinning and the twinning intersections. However, it should be confirmed here that the decrease in the BDT temperature by changing the specimen orientation is not due to the difference in the geometry of the specimens shown in Figs. 2(a) and 2(b). Since the ability to accommodate stress concentration at the notch tip should depend on the relation between a notch and slip systems. If the decrease in the BDT temperature is due to the change in crystallographic relation between the notch and slip planes, the BDT temperature in $\mathrm{Fe}-4 \% \mathrm{Al}$ also should be decreased when the longitudinal direction of the specimen is also set to be along [110]. However, as shown in Fig. 6, the BDT temperature of $\mathrm{Fe}-4 \% \mathrm{Al}$ was increased to be approximately $200 \mathrm{~K}$ from $140 \mathrm{~K}$ of that in Fig. 3. There are also no apparent twinning intersections at the side surfaces of the specimen as shown in Figs. 7(c) and $7(\mathrm{~d})$ at any temperature. Those results demonstrate that the effect of the change in the specimen geometry in Fe$4 \% \mathrm{Al}$ is to increase the BDT temperature, which is contrary to the results in $\mathrm{Fe}-8 \% \mathrm{Al}$, so that the decrease in the BDT temperature in $\mathrm{Fe}-8 \% \mathrm{Al}$ is not due to the effect of the specimen geometry but the effect of suppressing deformation twinning. This experimentally clarifies that the twinning intersection increases the BDT temperature in $\mathrm{Fe}-\mathrm{Al}$ alloys. It can be concluded here that deformation twinning was facilitated by increasing in the amount of aluminium, which increased the BDT temperature whereas aluminium induces solid solution softening in steel at low temperatures. The question raised here is that why deformation twinning were facilitated by aluminium.

\section{Discussion}

There are two factors to be considered for understanding the occurrence of deformation twinning; (1) the onset shear stress for deformation twinning, i.e. twinning stress, $\tau_{T} ;$ (2) the competition between the onset of deformation twinning and the slip deformation. Regarding to the onset stress of deformation twinning, the change in twinning stress with aluminium content should be discussed first, however, there are no data of twinning stress available for $\mathrm{Fe}-\mathrm{Al}$ alloys. Then, the results on twinning stress obtained from $\mathrm{Fe}-\mathrm{Si}$ alloys are used instead. This analogical consideration can be reasonable since silicon induces both solid solution softening and the increase in the BDT temperature as well as aluminium. Narita et al. ${ }^{10)}$ measured the twinning stresses of Fe-Si single crystals and demonstrated that twinning stress increased with silicon contents from $2.5 \%$ to $4.5 \%$. It suggests that twinning stress would increase also with aluminium contents, indicating that twinning deformation becomes difficult as the increase in aluminium content. This contradicts to the experimental results that deformation twinning was enhanced by the increasing in aluminium contents. Therefore, one needs to take into account the second factor that the competition between deformation twinning and slip deformation, in order to understand why aluminium increases the BDT temperature while it also induces solid solution softening.

Figure 8 schematically indicates the temperature dependences of twinning stress and slip deformation stress in Fe-
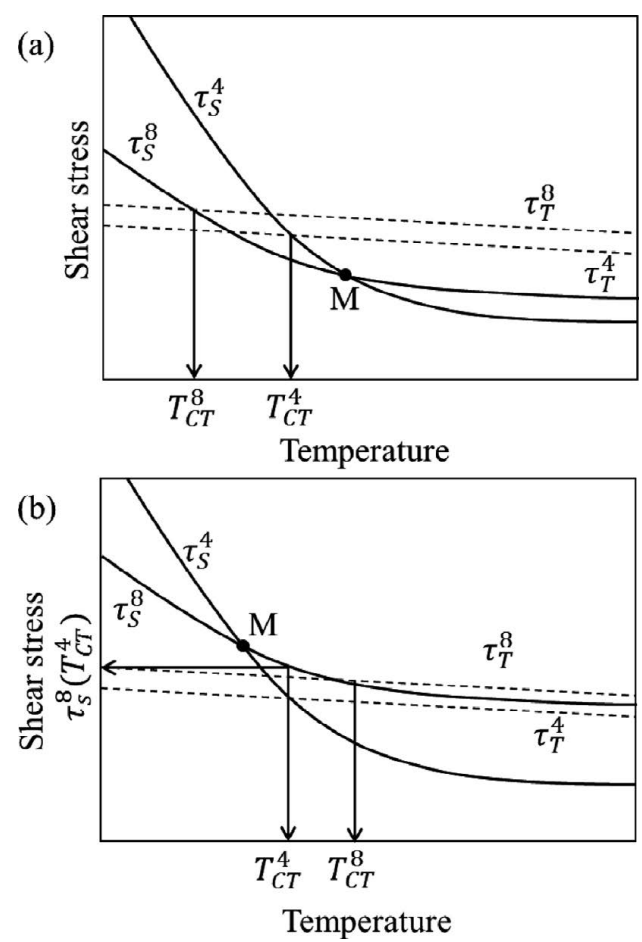

Fig. 8. Schematic drawing of twinning stress and slip deformation stress. Twinning stress for $\mathrm{Fe}-4 \% \mathrm{Al}$ and $\mathrm{Fe}-8 \% \mathrm{Al}$ are denoted by $\tau_{T}^{4}$ and $\tau_{T}^{8}$, respectively, while slip deformation stress for $\mathrm{Fe}-4 \% \mathrm{Al}$ and $\mathrm{Fe}-8 \% \mathrm{Al}$ are denoted by $\tau_{S}^{4}$ and $\tau_{S}^{8}$, respectively. $T_{C T}^{4}$ denotes the temperature at which $\tau_{T}^{4}$ intersects with $\tau_{S}^{4}$ while $T_{C T}^{8}$ denotes the temperature at which $\tau_{T}^{8}$ intersects with $\tau_{S}^{8} \cdot \tau_{S}^{8}\left(T_{C T}^{4}\right)$ denotes the value of $\tau_{S}^{8}$ at $T_{C T}^{4}$. It is speculated that the increase in the plateau stress of the slip deformation stress needs to be larger than that in the twinning stress, which increases the BDT temperature with the aluminum content.

4\%Al and $\mathrm{Fe}-8 \% \mathrm{Al}$. Here, twinning stress for $\mathrm{Fe}-4 \% \mathrm{Al}$ and $\mathrm{Fe}-8 \% \mathrm{Al}$ are denoted by $\tau_{T}^{4}$ and $\tau_{T}^{8}$ in the figure, respectively, while slip deformation stress for $\mathrm{Fe}-4 \% \mathrm{Al}$ and $\mathrm{Fe}-8 \% \mathrm{Al}$ are denoted by $\tau_{S}^{4}$ and $\tau_{S}^{8}$, respectively. The schematic illustrations in Fig. 8 were drawn, subjecting to following three conditions; (1) The slopes of $\tau_{S}^{4}, \tau_{S}^{8}>$ The slopes of $\tau_{T}^{4}, \tau_{T}^{8}$ : experimental results ${ }^{13)}$ show that the temperature dependence of slip deformation stress is larger than that of deformation twinning; (2) $\tau_{T}^{4}<\tau_{T}^{8}$ : twinning stress should be increased with aluminium content from the analogy with the results from $\mathrm{Fe}-\mathrm{Si}$ alloys $^{10)}$ as mentioned; (3) $\tau_{S}^{4}$ and $\tau_{S}^{8}$ intersect each other at some point of temperature: slip deformation stress consists of effective stress and internal stress. The effective stress depends on temperature while internal stress does not. Solute aluminium atoms weaken the temperature dependence of effective stress, which leads to solid solution softening at low temperatures. Slip deformation stress decreases with increasing temperature due to the decrease in the effective stress, and then the slip deformation stress saturates at some level of stress (stress plateau). Gerberich and $\mathrm{Chen}^{8)}$ demonstrated that the plateau stress increased with silicon in Fe-Si alloys, which would be due to the increase in certain internal stress. At low temperature, the stress for slip deformation is decreased with the increase in silicon or aluminium content (solid solution softening) while at high temperatures it is increased with the content of silicon or aluminium (solid solution hardening), which 
makes $\tau_{S}^{4}$ and $\tau_{S}^{8}$ curves intersect each other at some temperature. It should be noted that the opposite behaviours at low and high temperatures is due to the different mechanism behind solid solution softening and solid solution hardening, i.e., the dominant barrier for dislocating glide is Peierls potential in low temperatures, ${ }^{14)}$ which dislocations can overcome as a thermally activated process, while that in room temperature is interactions between dislocations and solute atoms, ${ }^{15)}$ which dislocations might not overcome as the thermally activated process.

Here, suppose that specimens cleave from the intersection of deformation twins below the temperature at which twinning stress and slip deformation stress curves intersect each other in Figs. 8(a) and 8(b) since twinning stress is lower than slip deformation stress below that temperature. $T_{C T}^{4}$ denotes the temperature at which $\tau_{T}^{4}$ intersects with $\tau_{S}^{4}$ while $T_{C T}^{8}$ denotes the temperature at which $\tau_{T}^{8}$ intersects with $\tau_{S}^{8}$. The increase in twinning stress induces the decrease in the BDT temperature $\left(T_{C T}^{8}<T_{C T}^{4}\right)$ as indicated in Fig. 8(a), i.e., the increase in the aluminium content should decrease the BDT temperature, which contradicts to the experimental results in this study. It suggests that it is inevitable to also take into account of the change in the slip deformation stress with aluminium contents in order to consider the effect of aluminium on the increase in the BDT temperature. Here, $\tau_{S}^{8}\left(T_{C T}^{4}\right)$ in Fig. $8(\mathrm{~b})$ denotes the value of $\tau_{S}^{8}$ at $T_{C T}^{4}$. It is understood from Figs. 8(a) and 8(b) that a necessary and sufficient condition for $T_{C T}^{8}$ to be higher than $T_{C T}^{4}$ is that the intersection of $\tau_{T}^{8}$ and $\tau_{S}^{8}$ is lower than $T_{C T}^{8}$. This assumption can explain that increasing aluminium content induces the increase in the BDT temperature whereas solid solution softening is also seen with increasing aluminium content. The condition of the increase in the BDT temperature can be considered from Figs. 8(a) and 8(b) as follows. Focusing on the stress for slip deformation, $M$ is defined as the intersection of the $\tau_{S}^{4}$ curve with the $\tau_{S}^{8}$ curve. Suppose, plateau stress in $\tau_{S}^{8}$ increases such as that in Fig. 8(a) to $8(\mathrm{~b}), \tau_{S}^{8}$ is increased by the amount of plateau stress increased at all temperatures, and then $\mathrm{M}$ shifts to the upper left in the figure. It induces the increase in $T_{C T}^{8}$ since the intersection of $\tau_{T}^{8}$ and $\tau_{S}^{8}$ curves shift to the right, that is, BDT temperature increases as M shifts to the upper left in Fig. 8(b) compared with that in Fig. 8(a).

It can be thus concluded here that the reason why the BDT temperature increases with aluminium or silicon content is speculated that the amount of increase in plateau stress would be larger than that in twinning stress with the increase in the amount of solute aluminium. It induces the difficulty of slip deformation, which leads to the facilitation of deformation twinning at higher temperatures in $\mathrm{Fe}-8 \% \mathrm{Al}$. The detail of the mechanism behind the increase in the plateau stress is a problem left, which needs to be discussed elsewhere.

\section{Conclusion}

The effect of aluminium on the brittle-to-ductile transition behaviour was investigated. The temperature dependence of absorbed energy was measured in Fe-mass $4 \% \mathrm{Al}$ and $\mathrm{Fe}-$ mass $8 \% \mathrm{Al}$. The following results were obtained;

(1) The increase in aluminium concentration in ferritic steels increases the BDT temperature.

(2) The more number of deformation twins were seen in $\mathrm{Fe}-8 \% \mathrm{Al}$ in the lower-shelf. Twin-twin intersections were actually found to be crack initiation sites for cleavage in Fe$8 \% \mathrm{Al}$ while there were no apparent signs of twin-twin intersections seen in $\mathrm{Fe}-4 \% \mathrm{Al}$.

(3) When the deformation twinning was suppressed in $\mathrm{Fe}-8 \% \mathrm{Al}$, the BDT temperature decreased. It indicates that the deformation twinning increases the BDT temperature in Fe-Al single crystals.

(4) The BDT temperature increased with aluminium whereas the increase in aluminium induces solid solution softening at low temperatures, which can be explained by the speculation that the amount of increase in plateau stress would be larger than that in twinning stress with the increase in the amount of solute aluminium, inducing the difficulty of slip deformation and facilitation of twinning deformation.

\section{REFERENCES}

1) W. A. Spitzig and W. C. Leslie: Acta Metall., 19 (1971), 1143.

2) Y. T. Chen, D. G. Atteridge and W. W. Gerberich: Acta Metall., 29 (1981), 1171.

3) J. Syarif, T. Tsuchiyama and S. Takaki: ISIJ Int., 43 (2003), 1100.

4) C. St. John: Philos. Mag., 32 (1975), 1193.

5) M. Brede and P. Haasen: Acta Metall., 36 (1988), 2003.

6) P. B. Hirsch, S. G. Roberts and J. Samuels: Proc. R. Soc. Lond. A, 421 (1989), 25.

7) G. Michot, M. A. L. de Oliveira and G. Champier: Mater. Sci. Eng. A, 272 (1999), 83.

8) W. W. Gerberich, Y. T. Chen, D. G. Atteridge and T. Johnson: Acta Metall. Mater., 29 (1981), 1187.

9) R. Honda: J. Phys. Soc. Jpn., 16 (1961), 1309.

10) N. Narita, K. Higashida and H. Kita: J. Soc. Mater. Sci., 36 (1987), 854.

11) K. Okazaki: J. Mater. Sci., 31 (1996), 1087.

12) S. Takeuchi, H. Yoshida and T. Taoka: Trans. JIM, 9, Suppliment (1968), 715.

13) N. Narita and J. Takamura: Dislocations in Solids, vol. 9, ed by F. R. N. Nabarro, North-Holland Publishing Company, Amsterdam, New York, Oxford, (1992), 178.

14) A. Seeger: Philos. Mag., 1 (1956), 651.

15) S. Takeuchi: J. Phys. Soc. Jpn., 27 (1969), 929. 